\title{
Substituição do milho pela silagem de jaca em dietas para cordeiros confinados
}

\section{Replacement corn for jackfruit silage in diets for feedlot lambs}

\author{
José Augusto Gomes Azevêdo ${ }^{1 *}$; Lígia Lins Souza ${ }^{2}$; Michelle Patrícia Frazer Salt²; \\ Leandro Silva Nascimento ${ }^{3}$; Flávio Moreira de Almeida ${ }^{4}$; Luiz Gustavo Ribeiro \\ Pereira $^{5}$; Robério Rodrigues Silva ${ }^{6}$; Gisele Andrade de Oliveira ${ }^{1}$; Diêgo Mendes \\ Freitas Ferreira $^{3}$; Vitor Visintin Silva de Almeida ${ }^{7}$
}

\section{Resumo}

Objetivou-se avaliar a substituição do milho pela silagem de jaca sobre o consumo, coeficiente de digestibilidade aparente e desempenho em dietas para cordeiros confinados. Foram utilizados cordeiros mestiços Santa Inês, machos castrados, em delineamento inteiramente casualizado. Os níveis de substituição foram $0,333,666,1000 \mathrm{~g} \mathrm{~kg}^{-1}$ na matéria seca (MS) do milho como componente do concentrado. Os consumos de MS, proteína bruta (PB) $\left(\mathrm{g} \mathrm{dia}^{-1}\right)$, e fibra em detergente neutro (FDN) em $\mathrm{g} \mathrm{kg}^{-1}$ e $\mathrm{g} \mathrm{kg}^{-1}$ peso corporal (PC), aumentaram linearmente com a substituição. Os consumos de matéria orgânica $(\mathrm{MO})$, extrato etéreo $(\mathrm{EE})$, carboidratos totais $(\mathrm{CT})$ e carboidratos não fibrosos $(\mathrm{CNF})$ diminuíram linearmente, enquanto para nutrientes digestíveis totais (NDT) apresentou comportamento quadrático com a substituição. Os coeficientes de digestibilidade aparente da MO, CT e CNF diminuíram linearmente com a substituição, enquanto o coeficiente de digestibilidade da PB e NDT apresentaram comportamento quadrático em função dos níveis de substituição. O PC final e o ganho médio diário diminuíram linearmente com a substituição do milho pela silagem de jaca. A silagem de jaca pode ser utilizada em substituição ao milho nas dietas dos cordeiros e seu uso fica dependente de fatores econômicos, da disponibilidade da fruta e do propósito de produtividade animal que se deseja alcançar. Palavras-chave: Alimentos alternativos, ruminante, valor nutritivo

\begin{abstract}
The objective was to evaluate the effects of replacement corn by jackfruit silage on intake, coefficient of apparent digestibility and performance in diets for feedlot confined lambs. Santa Inês crossbred castrated male lambs were used, in the completely randomized design. The replacement levels were 0. 333. 666. $1000 \mathrm{~g} \mathrm{~kg}^{-1}$ in dry matter (DM) of corn as the concentrate component. The intake DM, crude protein (CP) $\left(\mathrm{g} \mathrm{day}^{-1}\right)$, neutral detergent fiber (NDF) in $\mathrm{g} \mathrm{kg}^{-1}$ and $\mathrm{g} \mathrm{kg}^{-1}$ body weight (BW) increased linearly with replacement. The intake of organic matter $(\mathrm{OM})$, ethereal extract (EE), total carbohydrates (TC) and non-fiber carbohydrates (NFC) decreased linearly, while for total digestible
\end{abstract}

1 Profs., Universidade Estadual de Santa Cruz, UESC, Ilhéus, BA. E-mail: augustog@uesc.br; gibbao@yahoo.com

2 Discentes do Curso de Mestrado em Zootecnia, Universidade Estadual do Sudoeste da Bahia, UESB, Itapetinga, BA. E-mail: ligia_lins@yahoo.com.br; michelle-salt@bol.com.br

3 Discentes do Curso de Graduação, UESC, Ilhéus, BA. E-mail: 1sn_19@hotmail.com.br; diegomendes.medvet@hotmail.com

4 Discente de Mestrado em Ciência Animal, UESC, Ilhéus, BA. E-mail: flavi_vet@yahoo.com.br

5 Pesquisador, Empresa Brasileira de Pesquisa Agropecuária, EMBRAPA, Gado de Leite, Juiz de Fora, MG. E-mail: luiz.gustavo@ embrapa.br

6 Prof., UESB, Itapetinga, BA. E-mail: rrsilva.uesb@hotmail.com

7 Prof., Instituto Federal de Educação, Ciência e Tecnologia Baiano, Santa Inês, BA. E-mail: vitor.almeida@si.ifbaiano.edu.br Autor para correspondência 
nutrients (TDN) quadratic behavior with replacement. The coefficients of apparent digestibility of OM, TC and NFC decreased linearly with replacement, while the coefficient of digestibility of CP and TDN showed quadratic behavior with replacement. The BW and average daily gain decreased linearly with the replacement of corn for jackfruit silage. The jackfruit silage can be used to replace corn in diets of lambs and their use is dependent on economic factors, the availability of fruit and purpose of animal productivity to be reached.

Key words: Alternative feeds, ruminant, nutritional value

\section{Introdução}

No confinamento dos cordeiros, a alimentação é responsável por parte significativa dos custos de produção e o milho é o ingrediente energético mais utilizado. Porém, por ser uma commodity agrícola, o milho tem seu preço atrelado ao mercado internacional, o que pode gerar incertezas sobre seu uso nas dietas dos cordeiros, existindo demanda por fontes de alimentos alternativos que possuam disponibilidade regional e que possam viabilizar economicamente a criação de cordeiros em qualquer região do país.

Pereira et al. (2007) ao avaliarem a composição bromatológica e digestibilidade in vitro de jaca (diferentes partes da infrutescência) das variedades, dura e mole, constataram semelhança e elevado valor nutritivo destas. As concentrações dos nutrientes observados foram: matéria seca (MS) de $294 \mathrm{~g} \mathrm{~kg}$ na matéria natural, $654 \mathrm{~g} \mathrm{~kg}^{-1}$ na MS de proteína bruta (PB), 271,50 $\mathrm{g} \mathrm{kg}^{-1}$ na MS de fibra em detergente neutro (FDN), 236,5 $\mathrm{g} \mathrm{kg}^{-1}$ na MS de fibra em detergente ácido (FDA), 109,70 $\mathrm{g} \mathrm{kg}^{-1}$ na MS de hemicelulose, $104 \mathrm{~g} \mathrm{~kg}^{-1}$ na MS de celulose e 4,63 $\mathrm{g} \mathrm{kg}^{-1}$ na MS de lignina. Além de elevados teores de digestibilidade da MS (85,2 e 83,9\% para jaca dura e mole, respectivamente).

Santos et al. (2008), apresentaram valores de composição bromatológica da silagem de jaca, com 510,00 $\mathrm{g} \mathrm{kg}^{-1}$ de matéria seca; 68,3g kg-1 de PB; $303,1 \mathrm{~g} \mathrm{~kg}^{-1}$ de FDN; 151,9 $\mathrm{g} \mathrm{kg}^{-1}$ de FDA e 413,2 $\mathrm{g} \mathrm{kg}^{-1}$ de carboidratos totais. Os autores avaliaram os níveis de inclusão da jaca desidratada de $0,5,10$, $15 \%$ no processo de ensilagem de gramíneas, como alternativa para reduzir as perdas por efluentes e como fonte de carboidratos solúveis para reduzir o $\mathrm{pH}$ e obter silagens de valor nutricional, obtendo resultados satisfatórios. De maneira semelhante, Silva et al. (2011) observaram que a inclusão de até $15 \%$ de jaca in natura à silagem de capim elefante melhorou a fermentação, a recuperação de MS e a composição bromatológica, reduzindo as perdas por gases durante o processo de ensilagem.

Para Azevêdo et al. (2012) a jaca (in natura e ensilada) apesar de pertencer a um grupo de alimentos alternativos com considerável quantidade de FDN, podem ser utilizadas como substituto parcial de cereais na dieta animal devido a alta digestibilidade de sua FDN.

Diante da escassez de trabalhos avaliando a silagem de jaca nas dietas de cordeiros em confinamento, objetivou-se avaliar os efeitos da substituição do milho no concentrado pela silagem de jaca sobre o consumo, coeficiente de digestibilidade aparente e desempenho em dietas para cordeiros confinados e comparar a cinética de fermentação ruminal in vitro do milho com a silagem de jaca.

\section{Material e Métodos}

O experimento foi conduzido no Laboratório de Pesquisa em Nutrição e Alimentação de Ruminantes (LaPNAR), da Universidade Estadual de Santa Cruz (UESC), em Ilhéus-Bahia, durante o período de junho a setembro de 2011, e foi aprovado pela Comissão de Ética no Uso de Animais (CEUAUESC), com número do protocolo 012/2011.

Foram utilizados cordeiros mestiços Santa Inês, machos castrados, com peso corporal médio inicial de 26,2 $\pm 3,6 \mathrm{~kg}$, os quais foram previamente identificados e tratados contra ecto e endoparasitas. 
As dietas foram compostas por volumoso e concentrado na proporção 40:60, sendo o volumoso a silagem de capim elefante aditivada com $100 \mathrm{~g}$ $\mathrm{kg}^{-1}$ de farelo de milho na matéria natural. As dietas foram formuladas para serem isonitrogenadas (180 $\mathrm{g} \mathrm{kg}^{-1}$ de proteína bruta, na base da matéria seca).
As dietas experimentais consistiram de níveis de silagem de jaca em substituição ao milho no concentrado, nas proporções de $0,333,666$ e 1000 $\mathrm{g} / \mathrm{kg}^{-1}$ de matéria seca (Tabela 1 ). O concentrado foi formulado com milho e/ou silagem de jaca, farelo de soja, uréia e mistura mineral (Tabela 2).

Tabela 1. Composição química dos alimentos e concentrados utilizados nas dietas experimentais.

\begin{tabular}{lccccc}
\hline \multirow{2}{*}{ Item } & \multirow{2}{*}{$\begin{array}{c}\text { Silagem de capim } \\
\text { elefante }\end{array}$} & Silagem de jaca & \multicolumn{4}{c}{ Concentrados (g kg MS) em função do nível de } \\
\cline { 3 - 6 } silagem de jaca
\end{tabular}

FDNcp, Fibra em detergente neutro corrigida para cinzas e proteínas; CNF, Carboidratos não fibrosos.

${ }^{1} \mathrm{~g} \mathrm{~kg}$ de matéria natural; ${ }^{2} \mathrm{~g} \mathrm{~kg}$ de matéria seca.

Fonte: Elaboração dos autores.

Tabela 2. Proporção dos ingredientes e composição química das dietas experimentais.

\begin{tabular}{|c|c|c|c|c|}
\hline \multirow{2}{*}{ Ingredientes } & \multicolumn{4}{|c|}{ Nível de silagem de jaca $\left(\mathrm{g} \mathrm{kg}^{-1}\right.$ na matéria seca) } \\
\hline & 0 & 333 & 666 & 1000 \\
\hline Silagem de capim elefante & 400 & 400 & 400 & 400 \\
\hline \multicolumn{5}{|c|}{ Concentrado } \\
\hline Milho moído ${ }^{1}$ & 370 & 247 & 123 & 0 \\
\hline Silagem de Jaca ${ }^{1}$ & 0 & 123 & 247 & 370 \\
\hline Farelo de Soja ${ }^{1}$ & 205 & 205 & 205 & 205 \\
\hline Uréia: sulfato de amônia $9: 1^{1}$ & 1 & 1 & 1 & 1 \\
\hline Suplemento mineral ${ }^{1,3}$ & 15 & 15 & 15 & 15 \\
\hline \multicolumn{5}{|c|}{ Composição química } \\
\hline Matéria seca $^{2}$ & 645,1 & 568,8 & 479,0 & 399,6 \\
\hline Matéria orgânica ${ }^{1}$ & 935,1 & 936,9 & 929,1 & 926,3 \\
\hline Matéria mineral $^{1}$ & 64,9 & 63,1 & 70,9 & 73,7 \\
\hline Proteína bruta ${ }^{1}$ & 192,4 & 179,6 & 192,0 & 184,2 \\
\hline Extrato etéreo $^{1}$ & 45,2 & 41,1 & 44,1 & 42,6 \\
\hline Fibra em detergente neutro ${ }^{1}$ & 362,2 & 365,5 & 366,5 & 367,4 \\
\hline Carboidratos totais $^{1}$ & 697,5 & 716,2 & 693,0 & 699,5 \\
\hline Carboidrato não fibroso $^{1}$ & 335,3 & 350,7 & 326,4 & 332,0 \\
\hline Nutrientes digestíveis totais ${ }^{1 *}$ & 722,0 & 709,0 & 695,0 & 682,0 \\
\hline
\end{tabular}

${ }^{1} \mathrm{~g} \mathrm{~kg}^{-1}$ de matéria seca, ${ }^{2} \mathrm{~g} \mathrm{~kg}^{-1}$ de matéria natural.

${ }^{3}$ Níveis de garantia (nutrientes $/ \mathrm{kg}$ ): cálcio- $82 \mathrm{~g}$; enxofre-11,70 g; fósforo- $60 \mathrm{~g}$; magnésio- 13g; sódio- $132 \mathrm{~g}$; cobre- $350 \mathrm{mg}$; cobalto- $30 \mathrm{mg}$; cromo- $11,70 \mathrm{mg}$; ferro- 700mg; flúor máximo- $600 \mathrm{mg}$; iodo- $50 \mathrm{mg}$; manganês- $1200 \mathrm{mg}$; selênio- $15 \mathrm{mg}$ e zinco$2600 \mathrm{mg}$.

* Valores estimados de acordo a tabela de composição de alimentos de Valadares Filho et al. (2006).

Fonte: Elaboração dos autores. 
O capim elefante (Pennisetum purpureum Schum. cv. Napier) foi proveniente de capineira já estabelecida na Fazenda Experimental da UESC, e foi picado em partículas de $2 \mathrm{~cm}$. A silagem foi preparada com $100 \mathrm{~g}$ de farelo de milho $\mathrm{kg}^{-1} \mathrm{de}$ capim elefante, com base na matéria natural do capim elefante, adicionadas à forragem recémpicada. O material foi pesado e homogeneizado, sendo, posteriormente, compactado em bombonas de 120 L por meio de pisoteio. A abertura aconteceu após 56 dias de fermentação.

A jaca foi colhida na região de Ilhéus-BA e, posteriormente, foi picada em ensiladeira estacionária de forragens e ensilada em bombonas de 120 L e também, foi aberta após 56 dias de fermentação.

O experimento teve duração de 85 dias, sendo 15 dias para adaptação dos cordeiros às instalações e as dietas experimentais. Após o período de adaptação, os animais foram submetidos à dieta hídrica por 16 horas, pesados e, assim, considerados os pesos corporais inicias.

Os animais foram confinados em baias individuais, com dimensões de 0,80 x 1,20 m, providas de bebedouro e comedouro. As dietas foram fornecidas na forma de ração completa, às $08 \mathrm{~h} 00$ e às $16 \mathrm{~h} 00$, permitindo-se sobras de $50 \mathrm{a} 100$ $\mathrm{g} \mathrm{kg}^{-1}$ da matéria natural. Todo alimento fornecido, bem como as sobras, foi pesado para cálculo do consumo de matéria seca e demais nutrientes.

As pesagens dos cordeiros foram realizadas no início do experimento e a cada 14 dias, antes da primeira refeição, após jejum de alimento sólido de, aproximadamente, 16 horas. Ao completar 70 dias do período experimental, os cordeiros foram pesados para obtenção do ganho médio diário (GMD) e da conversão alimentar (CA).

Ao final do período experimental de desempenho, os cordeiros foram transportados para o procedimento de abate humanitário, que ocorreu na Unidade Experimental em Caprinos e Ovinos
(UECO) da Universidade Estadual do Sudoeste da Bahia, Itapetinga, Bahia.

As sobras foram retiradas, pesadas e amostradas diariamente, além disso, foram coletadas amostras diárias dos alimentos fornecidos, e foi realizada uma amostra composta a cada período de 14 dias, que foram identificadas e acondicionadas em freezer, para posteriores análises laboratoriais.

Ao final do experimento, as amostras foram descongeladas à temperatura ambiente. Posteriormente, foram pré-secas em estufa de circulação forçada de ar a $60 \pm 5^{\circ} \mathrm{C}$ por 72 horas e processadas em moinho de faca tipo Willey, usando peneira de $1 \mathrm{~mm}$, para posteriores análises do conteúdo de matéria seca (MS), proteína bruta (PB), matéria mineral $(\mathrm{MM})$, extrato etéreo $(\mathrm{EE})$ e fibra em detergente ácido (FDA), conforme os métodos do AOAC (1990).

Nas análises de fibra em detergente neutro (FDN), as amostras foram tratadas com alfa-amilase termoestável, sem o uso de sulfito de sódio e corrigidas para cinzas residuais (MERTENS, 1992). A fibra em detergente neutro, isenta de cinzas e proteínas (FDNcp), foi calculada segundo Mertens (1992) e os compostos nitrogenados insolúveis nos detergentes neutro (NIDN) e ácido (NIDA) foram determinados conforme Licitra, Hernandez e Van Soest (1996).

Os carboidratos totais (CT) foram estimados conforme recomendação Sniffen et al. (1992) e os nutrientes digestíveis totais (NDT) foram calculados segundo Weiss (1999), mas utilizando a FDN e os CNF corrigidos para cinza e proteína.

O consumo voluntário de MS e dos demais componentes da dieta foram calculados pela diferença entre as quantidades oferecidas e as sobras. Foi estimado o consumo de MS, MO, PB, EE, FDNcp, CT, CNF e NDT, em kg dia, g kg do peso corporal (PC) e a conversão alimentar (CA). 
A coleta de amostras de fezes foi realizada em três períodos durante o experimento, diretamente da ampola retal durante cinco dias consecutivos. As fezes foram pré-secas em estufa de ventilação forçada a $60 \pm 5^{\circ} \mathrm{C}$ por 72 horas e, posteriormente, processadas em moinho de peneira com crivo de $2 \mathrm{~mm}$ para futuras análises. A estimativa da produção de MS fecal foi feita utilizando-se a fibra em detergente ácido indigestível (FDAi) como indicador interno (COCHRAN et al., 1986). Para avaliação dos teores de componentes indigestíveis, os alimentos e as fezes foram acondicionados em sacos de tecido não-tecido (TNT - $100 \mathrm{~g} \mathrm{~m}^{-2}$ ). As amostras foram acondicionadas, em todos os sacos, na proporção de $20 \mathrm{mg}$ de $\mathrm{MS} / \mathrm{cm}^{2}$ de superfície e incubadas no rúmen de um bovino com fístula ruminal por 264 horas (CASALI et al., 2008). Após a retirada dos sacos do interior do rúmen, os sacos foram lavados com água corrente até total clareamento e imediatamente transferidos para estufa de ventilação forçada $\left(60 \pm 5^{\circ} \mathrm{C}\right)$, onde foram mantidos por 72 horas. Sequencialmente, foram secos em estufa não ventilada $\left(105^{\circ} \mathrm{C}\right.$ por 45 minutos), acondicionados em dessecador (20 sacos/ dessecador) e pesados (DETMANN et al., 2001) para obtenção da MS não-digerida. Posteriormente, os sacos foram tratados com detergente neutro por 1 hora, em autoclave, lavados com água quente e acetona, secos e pesados, conforme procedimento anterior, para quantificação da FDA indigestível (FDAi).

O delineamento experimental utilizado foi o inteiramente casualizado, com quatro dietas experimentais e quatro repetições, considerando cada cordeiro uma unidade experimental. Os dados foram submetidos à análise de variância e quando necessário à análise de regressão. Os modelos foram selecionados com base nos coeficientes de determinação e na significância dos coeficientes de regressão. Os dados obtidos sobre os parâmetros da produção dos gases dos $\mathrm{CNF}$ e $\mathrm{CF}$, foram ajustados por regressão não-linear pelo método de GaussNewton.
Utilizou-se o programa SAS (Statistical Analysis System) para os procedimentos estatísticos adotandose 0,05 como nível crítico de probabilidade para o erro tipo I.

\section{Resultados e Discussão}

Os valores de consumo de MS ( $\mathrm{kg}$ dia, $\mathrm{g} \mathrm{kg}^{-1}$ PC e $\left.\mathrm{g} \mathrm{kg}^{-1} \mathrm{PC}^{0,75}\right)$, PB e FDN ( $\mathrm{kg} \mathrm{dia}{ }^{-1}, \mathrm{~g} \mathrm{~kg}^{-1}$ $\mathrm{PC})$, aumentaram linearmente $(\mathrm{P}<0,05)$ em função dos níveis de substituição do milho por silagem de jaca (Tabela 3). Isto pode ser consequência da maior palatabilidade das dietas com silagem de jaca (KUSMARTONO, 2007). Outra característica importante da silagem de jaca é que por ser um alimento com menor teor de MS (20,96\%) em relação ao milho, possibilitou uma mistura mais homogênea, promovendo a união entre os concentrados e o volumoso, impedindo a seletividade dos alimentos e induzindo os cordeiros ao consumo da dieta como um todo.

Mesmo considerando que a silagem de jaca possuiu maior tamanho de partícula em relação ao milho, o que deveria reduzir a taxa de passagem e reduzir o consumo de MS, isto parece que não aconteceu, indicando que as dietas com silagem de jaca nos níveis utilizados neste experimento, não apresentam limitações de repleção ruminal. Provavelmente, a relação volumoso concentrado de 40:60 foi o fator determinante que fez com que esta fonte de fibra não tivesse provocado limitação ao CMS.

Visto que há semelhança na composição bromatológica da silagem de jaca (Tabela 1) com a palma forrageira em relação aos teores de FDNcp (26,9 e $29,1 \%)$, carboidratos totais $(81,3$ e $82,6 \%)$ e CNF (54,5 e 53,0\%), respectivamente, é válida a comparação entre estes alimentos.

Costa et al. (2012) ao avaliarem os efeitos da substituição de milho pela palma forrageira no desempenho de cordeiros Santa Inês, verificaram ingestão da palma forrageira de $1490 \mathrm{~g} \mathrm{dia}{ }^{-1}$, 
corroborando com os resultados encontrados consumiram mais silagem de jaca obtiveram maior no presente experimento, onde os animais que consumo de MS, consumindo $1487,96 \mathrm{~g} \mathrm{~kg}^{-1}$.

Tabela 3. Consumo dos nutrientes em função dos níveis de silagem de jaca em substituição ao milho.

\begin{tabular}{|c|c|c|c|c|c|c|c|}
\hline \multirow{2}{*}{ Variáveis } & \multicolumn{4}{|c|}{ Níveis de silagem de jaca $\left(\mathrm{g} \mathrm{kg}^{-1} \mathrm{MS}\right)$} & \multirow{2}{*}{$\mathrm{EPM}^{*}$} & \multirow{2}{*}{ Valor P } & \multirow{2}{*}{$\begin{array}{l}\text { Equação de } \\
\text { Regressão }\end{array}$} \\
\hline & 0 & 333 & 666 & 1000 & & & \\
\hline \multicolumn{8}{|c|}{ Consumo $\left(\mathrm{g} \mathrm{dia}^{-1}\right)$} \\
\hline Matéria Seca & 1212,77 & 1231,55 & 1428,78 & 1487,96 & 23,25 & 0,0009 & 1 \\
\hline Matéria Orgânica & 1167,21 & 1170,07 & 1155,02 & 1120,67 & 3,99 & $<0,0001$ & 2 \\
\hline Proteína Bruta & 258,29 & 269,59 & 371,61 & 497,96 & 18,11 & 0,0001 & 3 \\
\hline Extrato etéreo & 53,23 & 49,29 & 52,49 & 44,54 & 0,83 & $<0,0001$ & 4 \\
\hline FDN & 340,21 & 395,66 & 467,61 & 490,97 & 619,43 & 0,0004 & 5 \\
\hline Carboidratos totais & 855,68 & 854,91 & 731,63 & 576,44 & 19,05 & $<0,0001$ & 6 \\
\hline $\mathrm{CNF}$ & 515,47 & 459,25 & 288,49 & 175,83 & 25,73 & $<0,0001$ & 7 \\
\hline NDT & 823,42 & 809,68 & 722,77 & 792,16 & 12,48 & 0,0050 & 8 \\
\hline \multicolumn{8}{|c|}{ Consumo $\left(\mathrm{g} \mathrm{kg}^{-1} \mathrm{PC}\right)$} \\
\hline Matéria Seca & 38,9 & 40,0 & 46,0 & 50,7 & 0,12 & $<0,0001$ & 9 \\
\hline FDN & 10,8 & 13,0 & 15,2 & 16,8 & 0,06 & 0,0009 & 10 \\
\hline \multicolumn{8}{|c|}{ Consumo $\left(\mathrm{g} \mathrm{kg}^{-1} \mathrm{PC}^{0,75}\right)$} \\
\hline Matéria Seca & 90,70 & 94,27 & 108,57 & 117,70 & 0,68 & $<0,0001$ & 11 \\
\hline
\end{tabular}

FDN, fibra em detergente neutro; CNF, carboidratos não- fibrosos; NDT, nutrientes digestíveis totais;

${ }^{1} \hat{Y}=1225,49+0,07343 * X\left(r^{2}=0,905\right) ;{ }^{2} \hat{Y}=1173,62-0,03841 * X\left(r^{2}=0,781\right)$

${ }^{3} \hat{Y}=233,33+0,21907 * X\left(r^{2}=0,908\right) ;{ }^{4} \hat{Y}=53,12-0,00544 * X\left(r^{2}=0,563\right) ;$

${ }^{5} \hat{Y}=351,18+0,09525 * \mathrm{X}\left(\mathrm{r}^{2}=0,964\right) ;{ }^{6} \hat{\mathrm{Y}}=887,17-0,25204 * \mathrm{X}\left(\mathrm{r}^{2}=0,882\right)$;

${ }^{7} \hat{Y}=535,99-0,34729 * X\left(r^{2}=0,969\right) ;{ }^{8} \hat{Y}=830,55-0,16910 * X+0,0001068819 * \mathrm{X}^{2}\left(\mathrm{R}^{2}=0,565\right)$;

${ }^{9} \hat{Y}=3,74521+0,00111 * X\left(r^{2}=0,965\right) ;{ }^{10} \hat{Y}=1,07034+0,00060749 * X\left(r^{2}=0,994\right) ;$

${ }^{11} \hat{Y}=89,58029+0,02050 * X\left(r^{2}=0,957\right)$;

* Erro padrão de média

$\mathrm{X}=$ níveis de silagem de jaca.

Fonte: Elaboração dos autores.

Diante dos resultados do experimento, se for substituído todo o milho do concentrado pela silagem de jaca estima-se alteração de apenas 73,43 $\mathrm{g} \mathrm{dia}^{-1}$ a mais no consumo de MS e 95,25 $\mathrm{g} \mathrm{dia}^{-1}$ a mais de consumo de FDN em relação àqueles cordeiros que estiverem consumindo dietas com milho no concentrado. Portanto, as diferenças para consumo de MS e FDN entre as dietas com milho e silagem de jaca são inexpressíveis biologicamente.

Resultados semelhantes foram observados por Costa et al. (2012), que trabalharam com a avaliação dos efeitos da substituição de milho pela palma forrageira no desempenho de cordeiros Santa Inês, onde os valores de FDN encontrados na palma forrageira e no milho foram $312,00 \mathrm{~g} \mathrm{~kg}^{-1}$ da MS de
FDN e 112,00 $\mathrm{g} \mathrm{kg}^{-1}$ da MS de FDN respectivamente. Estes autores observaram um consumo de 20,1 $\mathrm{g}$ dia${ }^{1}$ de FDN kg-1 de peso corporal, com a proporção de palma forrageira na dieta devido a maior quantidade de FDN na mesma, apesar do consumo de FDN ser de 20,1 $\mathrm{g} \mathrm{dia}^{-1}$ de FDN kg-1 de peso corporal, a fermentação ruminal não foi prejudicada, devido à palma forrageira apresentar a digestibilidade de $92,82 \%$.

Já para o consumo de $\mathrm{PB}$, as influências da substituição do milho pela silagem de jaca foram maiores e estimou-se que a completa substituição poderá acrescentar 219,07 g de $\mathrm{PB}$ dia $^{-1}$ nas dietas com substituição completa do milho pela silagem de jaca em relação à dieta sem silagem de jaca, o que 
pode estar relacionado ao concentrado formulado para este nível.

Os consumos de MO, EE, CT e CNF diminuíram $(\mathrm{P}<0,05)$ linearmente com a substituição do milho pela silagem de jaca. No entanto, a completa substituição do milho pela silagem de jaca reduziu em apenas 38,41 $\mathrm{g} \mathrm{dia}^{-1}$ no consumo de $\mathrm{MO}$ e 5,44 $\mathrm{g}$ dia $^{-1}$ no consumo de EE em relação àqueles cordeiros que estiverem consumindo dietas com milho no concentrado e isto pode ter sido influenciado pelo efeito da palatabilidade da silagem de jaca que induziu os cordeiros a consumirem toda a dieta incluindo todo suplemento mineral.

Já as diferenças $(\mathrm{P}<0,05)$ observadas com a completa substituição do milho pela silagem de jaca foram de 252,04 $\mathrm{g} \mathrm{dia}^{-1}$ a menos no consumo de CT e de até $347,92 \mathrm{~g} \mathrm{dia}^{-1}$ a menos no consumo de $\mathrm{CNF}$ em relação àqueles cordeiros que estiverem consumindo dietas à base de milho no concentrado. Isto indica maior suprimento de energia nas dietas sem silagem de jaca o que poderá refletir no desempenho destes animais.
O consumo de nutrientes digestíveis totais apresentou efeito quadrático $(\mathrm{P}<0,05)$ com valor mínimo de $629,90 \mathrm{~g} \mathrm{~kg}^{-1}$ ou 49,07\% de NDT para o nível de 791,05 $\mathrm{g} \mathrm{kg}^{-1}$ de inclusão da silagem de jaca em substituição ao milho, isso pode ter ocorrido devido à diminuição do consumo dos carboidratos totais e não fibrosos. No entanto, dietas com 333 $\mathrm{g} \mathrm{kg}^{-1}$ de substituição do milho pela silagem de jaca proporcionaram aos cordeiros $786,09 \mathrm{~g} \mathrm{dia}^{-1}$ de NDT ou $62,89 \%$ de NDT e quando comparado a dietas isentas de silagem de jaca as diferenças foram de 5,35\%, isto é, os cordeiros sem silagem de jaca na dieta consumiram $830,55 \mathrm{~g} \mathrm{dia}^{-1}$ de NDT ou $67,77 \%$ de NDT.

Não foi observado influência $(\mathrm{P}>0,05)$ da adição de silagem de jaca na dieta para o coeficiente de digestibilidade aparente da MS, EE e FDN, apresentando valor médio de 62,06; 60,62 e 44,61g $\mathrm{kg}$, respectivamente (Tabela 4), indicando que a silagem de jaca possui digestibilidade equivalente ao milho para estes nutrientes.

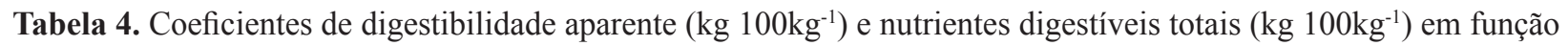
dos níveis de silagem de jaca em substituição ao milho no concentrado.

\begin{tabular}{lccccccc}
\hline \multirow{2}{*}{ Item } & \multicolumn{4}{c}{$\begin{array}{c}\text { Nível de silagem de jaca } \\
\left(\mathrm{g} \mathrm{kg}^{-1} \mathrm{MS}\right)\end{array}$} & \multirow{2}{*}{ EPM* $^{*}$} & Valor P & $\begin{array}{c}\text { Equação de } \\
\text { Regressão }\end{array}$ \\
\cline { 2 - 5 } & 0 & 333 & 666 & 1000 & & & \\
\hline Matéria seca & 63,49 & 63,04 & 60,62 & 61,25 & 0,66 & 0,3665 & $\hat{\mathrm{Y}}=62,06$ \\
Matéria orgânica & 66,61 & 58,97 & 57,59 & 65,92 & 1,19 & 0,0037 & 1 \\
Proteína bruta & 74,23 & 71,60 & 73,80 & 80,65 & 1,07 & 0,0097 & 2 \\
Extrato etéreo & 68,33 & 61,81 & 50,46 & 54,33 & 2,81 & 0,1098 & $\hat{\mathrm{Y}}=60,62$ \\
Fibra em detergente neutro & 38,43 & 45,23 & 45,09 & 49,62 & 1,52 & 0,0754 & $\hat{\mathrm{Y}}=44,61$ \\
Carboidratos totais & 64,13 & 64,29 & 53,38 & 51,70 & 1,41 & 0,0001 & 3 \\
Carboidratos não fibrosos & 80,88 & 78,14 & 65,10 & 65,39 & 2,03 & 0,0026 & 4 \\
Nutrientes digestíveis totais & 68,01 & 66,31 & 52,28 & 67,72 & 1,87 & 0,0012 & 5 \\
\hline
\end{tabular}

${ }^{1} \hat{Y}=66,17296-0,00288 * X\left(r^{2}=0,767\right) ;{ }^{2} \hat{Y}=74,31594-0,01672 * X+0,00003008 * X^{2}\left(R^{2}=0,999\right) ;$

${ }^{3} \hat{Y}=65,55329-0,01416 * \mathrm{X}\left(\mathrm{r}^{2}=0,847\right) ;{ }^{4} \hat{\mathrm{Y}}=81,50843-0,01826 * \mathrm{X}\left(\mathrm{r}^{2}=0,864\right)$;

${ }^{5} \hat{Y}=69,36251-0,03081 * X+0,00002465 * X^{2}\left(R^{2}=0,499\right)$

* Erro padrão de média

$\mathrm{X}=$ níveis de silagem de jaca.

Fonte: Elaboração dos autores. 
Embora tenha aumentado a porção fibrosa das rações com a inclusão de silagem de jaca, esta é de alta digestibilidade, o que provavelmente ocasionou a ausência do efeito no coeficiente de digestibilidade da matéria seca com a inclusão de silagem de jaca em substituição ao milho no concentrado.

O coeficiente de digestibilidade aparente da $\mathrm{MO}, \mathrm{CT}$ e CNF diminuiu linearmente $(\mathrm{P}<0,05)$ com a substituição do milho pela silagem de jaca, com reduções de 2,88; 14,16 e 18,26\%, respectivamente, se comparado a substituição completa do milho pela silagem de jaca em relação à dieta sem silagem de jaca. Estes resultados podem ser consequência do tipo de CT e CNF entre o milho e a silagem de jaca, já que a base destes carboidratos no milho é o amido e na silagem de jaca é a pectina (HAQ; BOWE; CLARKE, 2008). O acesso para aproveitamento das duas fontes pode ter limitado o melhor aproveitamento das dietas a base de silagem de jaca em relação às dietas com milho. Pois, de acordo com Hall (1994), a pectina é classificada como carboidrato estrutural e não fibroso. Está localizada na lamela média da parede celular vegetal e funciona como substância de adesão entre as células, sendo, em parte responsável pela rigidez dos tecidos vegetais. Diferente do amido, a pectina não é digerida por enzima animal. Dessa forma, pode-se explicar a menor digestibilidade aparente da MO, CT e CNF das dietas com silagem de jaca quando comparada com o milho, devido ao menor acesso das bactérias ruminais à pectina.

Resultados encontrados por Véras, Ferreira e Carvalho (2005), que avaliaram o consumo e digestibilidade do farelo de palma forrageira em substituição ao milho para ovinos em crescimento, também verificaram redução da digestibilidade aparente da MO com inclusão de farelo de palma substituindo o milho, em razão da maior concentração de CNF no milho. Um dos benefícios do amido presente no milho é a maior disponibilidade de energia no rúmen e consequentemente, maior produção de proteína microbiana.
Para o nível de 277,92 $\mathrm{g} \mathrm{kg}^{-1}$ de silagem de jaca em substituição ao milho, foi observado comportamento quadrático $(\mathrm{P}<0,05)$ para digestibilidade da $\mathrm{PB}$, com valor mínimo de 71,99 (Tabela 4), por ser a dieta que apresentava menor quantidade de jaca, é possível que não tenha havido união dos alimentos, e consequentemente, os animais não terem consumido e aproveitado totalmente a composição proteica, uma vez que a silagem de jaca promove a união entre concentrado e volumoso, dificultando a seletividade dos alimentos.

$\mathrm{O}$ teor de nutrientes digestíveis totais apresentou comportamento quadrático $(\mathrm{P}<0,05)$, com valor mínimo de 59,73 $\mathrm{g} \mathrm{kg}^{-1}$ para o nível 624,94 g $\mathrm{kg}^{-1}$. De acordo com os resultados obtidos, a forma de aproveitamento do NDT, pode refletir no desempenho animal. Uma vez que, a maior digestibilidade dos ingredientes e maiores valores de NDT, estão relacionados a maiores ganhos de peso (BARROSO et al., 2006). Dessa forma, o aproveitamento do NDT é de extrema importância para o perfeito atendimento das exigências dos animais e consequentemente desempenho produtivo.

Observou-se que os cordeiros alimentados com dietas substituindo milho pela silagem de jaca apresentaram menor $(\mathrm{P}<0,05)$ ganho médio diário e peso vivo final (Tabela 5). Tal comportamento pode ser explicado pela redução do NDT na dieta com a substituição do milho pela silagem de jaca. Estes resultados estão de acordo com os observados por Costa et al. (2012) os quais encontraram que os ovinos que se alimentaram de dietas dos níveis de $1000 \mathrm{~g} \mathrm{~kg}^{-1}$ ganharam $0,210 \mathrm{~kg} \mathrm{dia}^{-1}$ e o ganho médio diário dos animais dos níveis de $0 \mathrm{~g} \mathrm{~kg}^{-1}$ foi $0,255 \mathrm{~kg} \mathrm{dia}^{-1}$, ou seja houve uma redução de 0,045 $\mathrm{kg} \mathrm{dia}^{-1}$.

A conversão alimentar é definida como sendo a razão entre o CMS e o GMD, representando a eficiência com que o animal transforma o alimento em proteína de origem animal. Assim, se o consumo de matéria seca aumentou e ganho de peso diminuiu ao adicionar jaca substituindo o milho, o que 
resultou na piora da conversão alimentar $(\mathrm{P}<0,05)$ com a substituição do milho pela silagem de jaca de forma que os animais consumindo $1000 \mathrm{~g}$ de silagem de jaca na dieta precisaram consumir 4,5 $\mathrm{kg}$ de alimento, a mais que os animais consumindo apenas milho para ganhar $1 \mathrm{~kg}$.

Tabela 5. Desempenho de cordeiros em função dos níveis de silagem de jaca em substituição ao milho.

\begin{tabular}{|c|c|c|c|c|c|c|c|}
\hline \multirow[b]{2}{*}{ Item } & \multicolumn{4}{|c|}{$\begin{array}{l}\text { Nível de silagem de jaca } \\
\left(\mathrm{g} \mathrm{kg}^{-1} \mathrm{MS}\right)\end{array}$} & \multirow[b]{2}{*}{ EPM* } & \multirow[b]{2}{*}{ Valor $\mathrm{P}$} & \multirow[b]{2}{*}{$\mathrm{ER}$} \\
\hline & 0 & 333 & 666 & 1000 & & & \\
\hline Peso corporal inicial $(\mathrm{kg})$ & 26,10 & 26,48 & 26,60 & 25,48 & 0,8 & & \\
\hline Peso corporal final $(\mathrm{kg})^{2}$ & 38,92 & 38,33 & 35,06 & 35,94 & 10,88 & 0,0333 & 3 \\
\hline Ganho médio diário $(\mathrm{g} / \mathrm{dia})^{2}$ & 180,57 & 172,10 & 125,48 & 137,66 & 8,44 & 0,0333 & 4 \\
\hline Conversão alimentar & 7,28 & 7,88 & 11,97 & 11,17 & 0,7 & 0,0027 & 5 \\
\hline
\end{tabular}

${ }^{1} \mathrm{~kg}$ de CMS kg-1 de ganho de peso, *- Erro padrão de média, ${ }^{2}$ Médias ajustadas por co-variância de peso corporal inicial. ${ }^{3} \hat{Y}=39,01557-0,03937 * X\left(r^{2}=0,717\right),{ }^{4} \hat{Y}=179,9873-0,52138 * X\left(r^{2}=0,717\right)$,

${ }^{5} \hat{Y}=7,25737+0,04656 X\left(r^{2}=0,752\right)$

$\mathrm{X}=$ nível de silagem de jaca

ER=Equação de regressão.

Fonte: Elaboração dos autores.

Conclui-se que a silagem de jaca pode ser utilizada em substituição ao milho nos concentrados das dietas dos cordeiros confinados e seu uso fica dependente de fatores econômicos, da disponibilidade da fruta e do propósito de produtividade zootécnica que se deseja alcançar.

\section{Referências}

ASSOCIATION OF OFFICIAL ANALYTICAL CHEMISTRY - AOAC. Official methods of analysis. 15. ed. Arlington: AOAC International, 1990. 1117 p.

AZEVÊDO, J. A. G.; VALADARES FILHO, S. C.; PINA, D. S.; DETMANN, E.; PEREIRA, L. G. R.; VALADARES, R. F. D.; FERNANDES, H. J.; COSTA e SILVA, L. F; BENEDETI, P. B. Nutritional diversity of agricultural and agro-industrial by-products for ruminant feeding. Arquivos Brasileiros de Medicina Veterinária e Zootecnia, Belo Horizonte, v. 64, n. 5, p. 1246-1255, 2012.

BARROSO, D. D.; ARAÚJO, G. G. L.; SILVA, D. S. S.; MEDINA, F. T. Resíduo desidratado de vitivinícolas associado a diferentes fontes energéticas na alimentação de ovinos: consumo e digestibilidade aparente. Ciência e Agrotecnologia, Lavras, v. 30, n. 4, p. 767-773, 2006.

CASALI, A. O.; DETMANN, E.; VALADARES FILHO, S. C.; PEREIRA, J. C.; HENRIQUES, L. T.; FREITAS, S. G.; PAULINO M. F. Influência do tempo de incubação e tamanho de partículas sobre os teores de compostos indigestíveis em alimentos e fezes bovinas obtidos por procedimento in situ. Revista Brasileira de Zootecnia, Viçosa, MG, v. 37, n. 2, p. 335-342, 2008.

COCHRAN, R. C.; ADMS, D. C.; WALLACE, J. D.; GALYEAN, M. L. Predicting digestibility of different diets with internal markes: Evaluation of four potential markers. Journal of Animal Science, Champaign, v. 63, n. 5, p. 1476-1483, 1986.

COSTA, R. G.; TREVINO, I. H.; MEDEIROS, G. R.; MEDEIROS, A. N.; PINTO, T. F.; OLIVEIRA, R. Effects of replacing corn with cactus pear (Opuntia ficus indica Mill) on the performance of Santa Inês lambs. Small Ruminant Research, Amsterdam, v. 102, n. 1, p. 13-17, 2012.

DETMANN, E.; PAULINO, M. F.; ZERVOUDAKIS, J. T.; VALADARES FILHO, S. C.; LANA, R. P.; QUEIROZ, D. S. Suplementação de novilhos durante a época das águas: parâmetros ingestivos e digestivos. Revista Brasileira de Zootecnia, Viçosa, MG, v. 30, n. 4, p. 1340-1349, 2001.

HALL, M. B. Pectin: the structural, non-structural carbohydrate. In: CORNELL NUTRITION CONFERENCE FOR FEED MANUFACTURES, 56., 1994, New York. Proceedings... New York: Cornell University, 1994. p. 29-36.

HAQ, N.; BOWE, C.; CLARKE, C. New crops and uses: their role in a rapidly changing world. In: SMARTT, J.; HAQ, N. (Ed.). A case for promotion of tropical 
underutilised fruits for improvement of livelihoods. Southampton: SO17 1BJ, UK. Centre for Underutilised Crops University of Southampton, 2008. p. 288-299.

KUSMARTONO. Effects of supplementing jackfruit (Artocarpus heterophyllus L) waste with urea or gliricidia/cassava leaves on growth, rumen digestion and feed degradability of sheep fed on rice straw basal. Livestock Research for Rural Development, Cali, v. 15, n. 1, p. 29-34, 2007

LICITRA, G.; HERNANDEZ, T. M.; VAN SOEST, P. J. Standardization of procedures for nitrogen fractionation of ruminant feeds. Animal Feed Science and Technology, Amsterdam, v. 57, n. 4, p. 347-358, 1996.

MERTENS, D. R. Análise da fibra e sua utilização na avaliação de alimentos e formulação de rações. In: SIMPÓSIO INTERNACIONAL DE RUMINANTES, 1992, Lavras. Anais... Lavras: Sociedade Brasileira de Zootecnia, 1992. p. 188-219.

PEREIRA, L. G. R.; MAURÍCIO, R. M.; AZEVÊDO, G. J. A, OLIVEIRA S. L.; BARREIROS, C. D.; FERREIRA, L. A.; BRANDÃO, N. L. G.; FIGUEIREDO P. M. Composição bromatológica e cinética de fermentação ruminal in vitro da jaca dura e mole (Artocarpus heterophyllus). Livestock Research for Rural Development, Cali, v. 19, n. 45, p. 7-12, 2007.

SANTOS, E. M.; ZANINE, A. M.; DANTAS, P. A. S.; DÓREA, J. R.; SILVA, T. C.; PEREIRA, O. G.; LANA, R. P.; COSTA, R. G. Composição bromatológica, perdas e perfil fermentativo de silagens de capim-elefante com níveis de inclusão de jaca. Revista Brasileira de Saúde Produção Animal, Salvador, v. 9, n. 1, p. 64-73, 2008.
SILVA, T. C.; DANTAS, P. A. S.; DÓREA, J. R. R.; SANTOS, E. M.; ZANINE, A. M.; PEREIRA, O. G. Populações microbianas, perfil fermentativo e composição de silagens de capim-elefante com jaca. Archivos de Zootecnia, Córdoba, v. 60, n. 230, p. 247255, 2011.

SNIFFEN, C. J.; O'CONNOR, J. D.; VAN SOEST, P. J.; FOXAND, D. G.; RUSSELL, J. B. A net carbohydrate and protein system for evaluating cattle diets: II. Carbohydrate and protein availability. Journal of Animal Science, Champaign, v. 70, n. 11, p. 3562-3577, 1992.

VALADARES FILHO, S. C.; MAGALHÃES, K. A.; ROCHA JÚNIOR, V. R.; CAPELLE, E. R. Tabelas brasileiras de composição de alimentos para bovinos. 2. ed. Viçosa: UFV, 2006. 329 p.

VÉRAS, R. M. L.; FERREIRA, M. A.; CARVALHO, F. F. R. C. Substituição do milho por farelo de palma forrageira em dietas para ovinos em crescimento. Consumo e digestibilidade. Revista Brasileira de Zootecnia, Viçosa, MG, v. 34, n. 1, p. 351-356, 2005.

WEISS, W. P. Energy predicton equations for ruminant feeds. In: CORNEL NUTRITION CONFERENCE FEED MANUFACTURES, 61., 1999, Ithaca. Proceedings... Ithaca: Cornell University, 1999. p. 176-185. 